\title{
Factors Influencing Childbearing Intentions among Female Employees of Department $M$ in the Public Sector in China under the "Two-Child" Policy
}

\author{
Ximing Yang \\ College of Social Science, University of Birmingham, Birmingham, England \\ Email: XXY912@student.bham.ac.uk
}

How to cite this paper: Yang, X. M. (2021). Factors Influencing Childbearing Intentions among Female Employees of Department $M$ in the Public Sector in China under the “Two-Child" Policy. Open Journal of Leadership, 10, 148-160.

https://doi.org/10.4236/ojl.2021.102010

Received: April 25, 2021

Accepted: June 8, 2021

Published: June 11, 2021

Copyright $\odot 2021$ by author(s) and Scientific Research Publishing Inc. This work is licensed under the Creative Commons Attribution International License (CC BY 4.0).

http://creativecommons.org/licenses/by/4.0/ (c) (i) Open Access

\begin{abstract}
Since China implemented a comprehensive two-child policy in October 2015, it has not reached the expected peak birth rate. Therefore, birth willingness, determining factors and policy optimization have become key topics of discussion and analysis. This study examined the factors influencing childbearing intentions among female employees of Department $\mathrm{M}$ in the Public Sector in China under the "Two-child" Policy Using a questionnaire survey and interview guide both capturing three dimensions that are individual basic information, actual marital status and family structure characteristics, data were collected from female employees of Department M in the Public Sector in China. Data were collected from 280 female employees. Logistic binary regression was carried out for quantitative data using SAS software while qualitative data were analysed using content analysis. The findings revealed that the influencing factors of the current female employees' willingness to bear children in the Department $M$ were marital factors, birth and support costs, growth environment, family conditions and external conditions. Therefore, it was concluded that the severe cost of childbirth and its own development situation will affect the willingness of female employees to bear children. And the recommendations of this study are that the government should pay more attention to the fertility environment of the whole society.
\end{abstract}

\section{Keywords}

Two-Child Policy, Public Sector, Logistic Binary Regression

\section{Introduction}

In recent years, the growth rate of the world's population has generally slowed 
down, and Chinese birth rate has continued to decline $(\mathrm{Wu}$, Huang, \& Pan, 2021). Although the seventh national census of China is underway, the results are expected to be announced in May. Only then will we be able to accurately understand Chinese current true population. However, previous data of the Ministry of Public Security of 2020 revealed that only 10.035 million newborns were registered in China. In 2019, the newborns were 14.65 million. This means that in 2020, it was about $15 \%$ lower than in 2019. In order to allow people to have more children, many organizations have introduced some incentive measures since the full liberalization of the second-child policy such as extending the time of maternity leave and providing bonuses (Clark, 2021). However, the effect has been minimal and instead a fertility cliff appeared. The effects of the second-child policy are shrinking with female workers in the public sector being be the group most affected. To establish the factors influencing childbearing intentions among female employees, this study used female employees of the department $M$. This research examines the implementation of the policy and rationality of the birth policy providing suggestions on how to optimise the fertility policy.

\section{Literature Review}

\subsection{Comprehensive Two-Child Policy and Reproductive Behavior}

The comprehensive two-child policy refers to the policy that allows couples among Chinese citizens to have two children regardless of city, township or ethnicity. The implementation of the comprehensive two-child policy aims to adjust Chinese existing population and demographic structure, and reduce the risks of aging to society. At the same time, it is also conducive to solving problems such as the short-term labor force, the imbalance of the gender ratio of the population, and the rising dependency ratio (Zeng \& Hesketh, 2016). Reproductive behavior is the conscious and purposeful production and reproduction of the lives of others under the control of fertility motivation. It is determined by the social environment in which it is located. It is both a natural physiological phenomenon and a social behavior (MacDonald, 1997).

\subsection{Theoretical Review}

The Three-Effect Theory proposed by American scholar Becker in the 1960s informed this study. The Three-Effect Theory posits that as the income effect increases along with the increase in prices and opportunity costs, the substitution effect increases, which inevitably lead to a decline in the fertility rate. On the other hand, economist Leibenstein (1974), through binary model analysis postulates that the reason why the population growth rate of some countries has not reached the expected rate depends on the value of children. Because with the development of the economy, there are more factors that can be substituted for the cost-effectiveness of children, which will then lead to a lower birth rate. And this article will also focus on what factors can replace the cost 
effect of children.

\subsection{Review of Related Literature}

When scholars began to discover that the adjustment of fertility policies was closely related to people's willingness to reproduce, they tried to demonstrate the factors that influence people's willingness to reproduce from the perspectives of economics and sociology.

Van De Kaa (2002) has successively published many articles since 1986, and was the first to propose and elaborate the "Theory of the Second Demographic Transition in Europe" (Van De Kaa, 2002). And in recent years, this theory has gradually been accepted by the public and aroused great repercussions. Its core content can be summarized as four points: 1) The life course of the diversification trend. 2) The marriage age is postponed, family forms are diversified, cohabitation is accepted by the public and treated equally with marriage, homosexuality is open and recognized by the public. 3) The relationship between the sexes in society is more equal. 4) Delayed childbearing age, reduced willingness to bear children, increased life-long infertility, and increased the proportion of out-of-marital births.

Scholars such as Stier, Lewin-Epstein and Braun (2012) analyzed the impact of social policies on conflicts between work and family by comparing the social policies of 27 countries, including fertility policies (Stier, Lewin-Epstein, \& Braun, 2012). Research shows that women face more conflicts than men. And the main factors affecting this conflict are working hours and child care issues. Therefore, convenient childcare services and flexible working hours for children can reduce women's sense of conflict to a certain extent and help balance the relationship between family and work.

Therefore, the current scholars' research on fertility and its influencing factors are quite successful. However, the disadvantage is that the current mainstream research focuses on theory and lacks quantitative research (Zhang \& Xia, 2017). These studies tend to be more theoretical and stream-of-conscious. It starts from the demography, sociology, and psychology levels, and has a higher level of guiding significance. However, the current problems facing China's second-child policy require a large amount of data to analyze the microscopic aspects of policy, economy, personal situation, family social environment and other micro aspects of different subjects and different regions of childbearing age groups. Therefore, this article combines the author's own internship experience in department $\mathrm{M}$, through relevant literature reading and on-site interviews, and refers to the two-factor theory to design questionnaires and interview outlines. Then it is convincing and innovative to use Logistic mathematical model to get the significant variables that affect the willingness of female employees in $\mathrm{M}$ department to bear children.

\section{Methodologies}

State the research design, indicate the population and how sampling was done. 


\section{Data Sources}

The data collection process is divided into five stages. The first is to explore the status quo. Secondly, the designed questionnaire was distributed to 20 female employees of different ages to fill in. Then modify the questionnaire based on their feedback and suggestions. Third, the questionnaire can be roughly divided into two parts because the content of the questionnaire is based on the two-factor theory. The first part is the basic situation of employees. The second part is about the issue of childbirth willingness. The fourth stage is the more difficult part of issuing questionnaires. In the end, the questionnaire was distributed to all female employees who knew the purpose of collecting the questionnaire in advance. Then collect the questionnaire, and use the binary logistic regression model to integrate and analyze the data according to the survey results of the questionnaire. Obtain the significant factors that affect the current female employees' willingness to give birth in the $M$ department. Thus, finally taking the $M$ department as an example, summarize the influencing factors that affect the current female employees' willingness to bear children in the public sector in China. Provide theoretical support and help for China to optimize and improve its fertility policy.

\section{Results}

\subsection{Response Rate}

A total of 285 questionnaires were distributed and recovered. After sorting them, 5 invalid questionnaires were eliminated and a total of 280 valid questionnaires were retained.

\subsection{Demographic Characteristics}

The results on the demographics of the respondents were on the basic information of the questionnaire is shown in Table 1.

Table 1 is a statistical table of basic information of female employees in department M. On the whole, the age composition of female employees in Department $\mathrm{M}$ is more reasonable. Among them, the number of female employees over 55 years old and the number of female employees under 26 years old accounted for only $13.9 \%$ and $9.3 \%$ of the entire department. According to Zhang et al. (2015), this age structure is in line with the age structure of most work units in China (Zhang et al., 2015). Therefore, it can be deduced that the results obtained were representative of the Chinese society.

From the perspective of marital status, the number of married people was much larger than the number of unmarried because the proportion of female employees over 35 is $65 \%$. On the other hand, the female employees of the Department $\mathrm{M}$ were concentrated in the undergraduate and master. This agrees with recent the Chinese government policy of attracting talent to the public sector. However, from the perspective of income level, the proportion of low-income people was higher, that is 164 were in the low-income category. And 
Table 1. Basic information form of female employees in department M.

\begin{tabular}{|c|c|c|c|c|c|c|}
\hline \multicolumn{2}{|c|}{ Marital Status } & \multicolumn{5}{|c|}{ Age } \\
\hline Married & Unmarried & $\leq 25$ years old & 26 - 35 years old & 36 - 45 years old & 46 - 55 years old & $\geq 56$ years old \\
\hline 219 & 61 & 26 & 72 & 97 & 46 & 39 \\
\hline \multicolumn{7}{|c|}{ Personal annual income } \\
\hline$<¥ 70,000$ & $\geq ¥ 70,000 \&<¥ 120,000$ & $\geq ¥ 120,000 \&<¥ 1$ & 70,000 & $120,000 \&<¥ 220,0$ & 000 & $\geq ¥ 220,000$ \\
\hline 164 & 72 & 15 & & 15 & & 14 \\
\hline \multicolumn{7}{|c|}{ Annual family income } \\
\hline$<¥ 70,000$ & $\geq ¥ 70,000 \&<¥ 220,000$ & $\geq ¥ 220,000 \&<¥ 3$ & 70,000 & $370,000 \&<¥ 520,0$ & & $\geq ¥ 520,000$ \\
\hline 52 & 152 & 51 & & 13 & & 12 \\
\hline \multicolumn{7}{|c|}{ Degree } \\
\hline High school and below & Junior college & Undergradua & & Master & & Doctor \\
\hline 4 & 30 & 140 & & 79 & & 27 \\
\hline \multicolumn{2}{|c|}{ Personal situation } & \multicolumn{5}{|c|}{ Currently raising children } \\
\hline No siblings & \multicolumn{2}{|c|}{ Have siblings } & Yes & \multicolumn{3}{|c|}{ No } \\
\hline 202 & \multicolumn{2}{|c|}{78} & 159 & \multicolumn{3}{|c|}{121} \\
\hline
\end{tabular}

it was difficult to judge whether such people are capable of having a second child. Finally, understanding some of the individual's family situation is also helpful to explore and analyze the factors that affect the willingness to have children.

According to the two-factor theory, the influencing factors of the questionnaire include personal situation factors and external influencing factors. In addition, the willingness of female employees in department $M$ can be divided into willingness and unwillingness. The willingness to give birth is assigned values of 0 and 1 . The responses of female employees in department $M$ to their willingness to give birth are shown in Table 2.

\section{Analysis Based on Logistic Regression Model}

\subsection{Select Model}

The questionnaire data of childbirth intention comes from every female employee in department $\mathrm{M}$. Therefore, a full understanding of the childbearing willingness of female employees in the department $\mathrm{M}$ is of great significance for exploring the childbearing willingness of female employees in the Chinese public sector. According to the two-factor theory, the female employees' willingness to have a second child in Department $\mathrm{M}$ can be divided into two variables: "There Fertility Desire" and "No Fertility Desire". According to Wright, Logistic regression models include binary regression models and multi-value regression models (Wright, 1995). Among them, the independent variable of the binary logistic regression model can be a numerical variable or a categorical variable. But the dependent variable must be a binary variable. Currently, this method has been 
Table 2. Survey results of judging quantity of fertility desire.

\begin{tabular}{ccccccc}
\hline \multirow{2}{*}{ Employee motivation } & \multicolumn{2}{c}{ Total sample $(\mathrm{n}=182)$} & \multicolumn{2}{c}{ There Fertility Desire sample $(\mathrm{n}=67)$} & \multicolumn{2}{c}{ No Fertility Desire sample $(\mathrm{n}=115)$} \\
\cline { 2 - 7 } & Average value & Standard deviation & Average value & Standard deviation & Average value & Standard deviation \\
\hline $\begin{array}{c}\text { Parents support having } \\
\text { a second child }\end{array}$ & 0.13 & 0.33 & 0.12 & 0.33 & 0.13 & 0.34 \\
Work pressure & 2.76 & 0.68 & 2.64 & 0.72 & 2.83 & 0.65 \\
Family atmosphere & 2.07 & 0.51 & 2.30 & 0.55 & 1.93 & 0.43 \\
Live with parents & 0.92 & 0.27 & 0.96 & 0.19 & 0.89 & 0.31 \\
Commuting time & 2.44 & 0.98 & 2.55 & 0.92 & 2.37 & 1.01 \\
Own house & 0.26 & 0.44 & 0.10 & 0.29 & 0.36 & 0.48 \\
Private time & 2.46 & 1.01 & 2.65 & 1.20 & 2.35 & 0.86 \\
\hline
\end{tabular}

widely used in various fields and industries. This model is not only the preferred analysis model for categorizing dependent variables. It can also better predict the willingness to bear children of female employees in department $M$ under different independent variables. Therefore, the Logistic regression model can predict the influence of various factors that affect the Fertility Desire of female employees in the Department M. And the group of employees who get the probability values of "There Fertility Desire" and "No Fertility Desire". The specific equations and formulas are transformed as follows:

$$
P_{i}=\frac{\exp \left(\alpha+\beta_{j} x_{j}+\varepsilon_{j}\right)}{1+\exp \left(\alpha+\beta_{j} x_{j}+\varepsilon_{j}\right)}
$$

Formula (1) can be further converted to Formula (2):

$$
\ln \frac{P_{i}}{1-P_{i}}=y_{i}=\alpha+\beta_{j} x_{j}+\varepsilon_{j}
$$

In Formula (1), $P_{i}$ represents the judgment probability of whether a female employee in department $\mathrm{M}$ is willing to have a second child, and the value is 0 and 1. Among them, $i=0,1.0$ means "There Fertility Desire" and 1 means "No Fertility Desire". $x_{j}$ represents the independent variable and $\beta_{j}$ represents the coefficient of the influencing factor. $\alpha$ represents the intercept and $\varepsilon_{j}$ represents the error $(j=1, \ldots, n)$.

\subsection{Variable Research}

The questionnaire can fully understand the status of the survey object and obtain real and effective data (Krosnick, 2018). Therefore, based on the feedback of the questionnaire and combined with the willingness of the female employees in the Department $\mathrm{M}$ to have a second child, the probability of the female employees who do not want to have a second child can be analyzed. Then we can propose effective solutions based on the independent variable factors influencing. In the questionnaire, the dependent variable question is set to "Are you currently willing to have a second child?" The answer is "Yes" and "Unwilling". Among the 
280 employees in the valid questionnaires, 105 employees chose "There Fertility Desire", accounting for $37.5 \%$ of the total valid questionnaires. There are 175 employees who choose "No Fertility Desire", accounting for $62.5 \%$ of the total valid questionnaires.

This article refers to "Age", "Degree", "Personal annual income", "Marital Status", "Annual family income”, "Personal situation", "Currently raising children", "Parents support having a second child", "Work pressure", "Family atmosphere", "Live with parents", "Commuting time", "Own house" and "Private time" as independent variables.

The assignment of the independent variable is shown in Table 3.

Table 3. Variable data description.

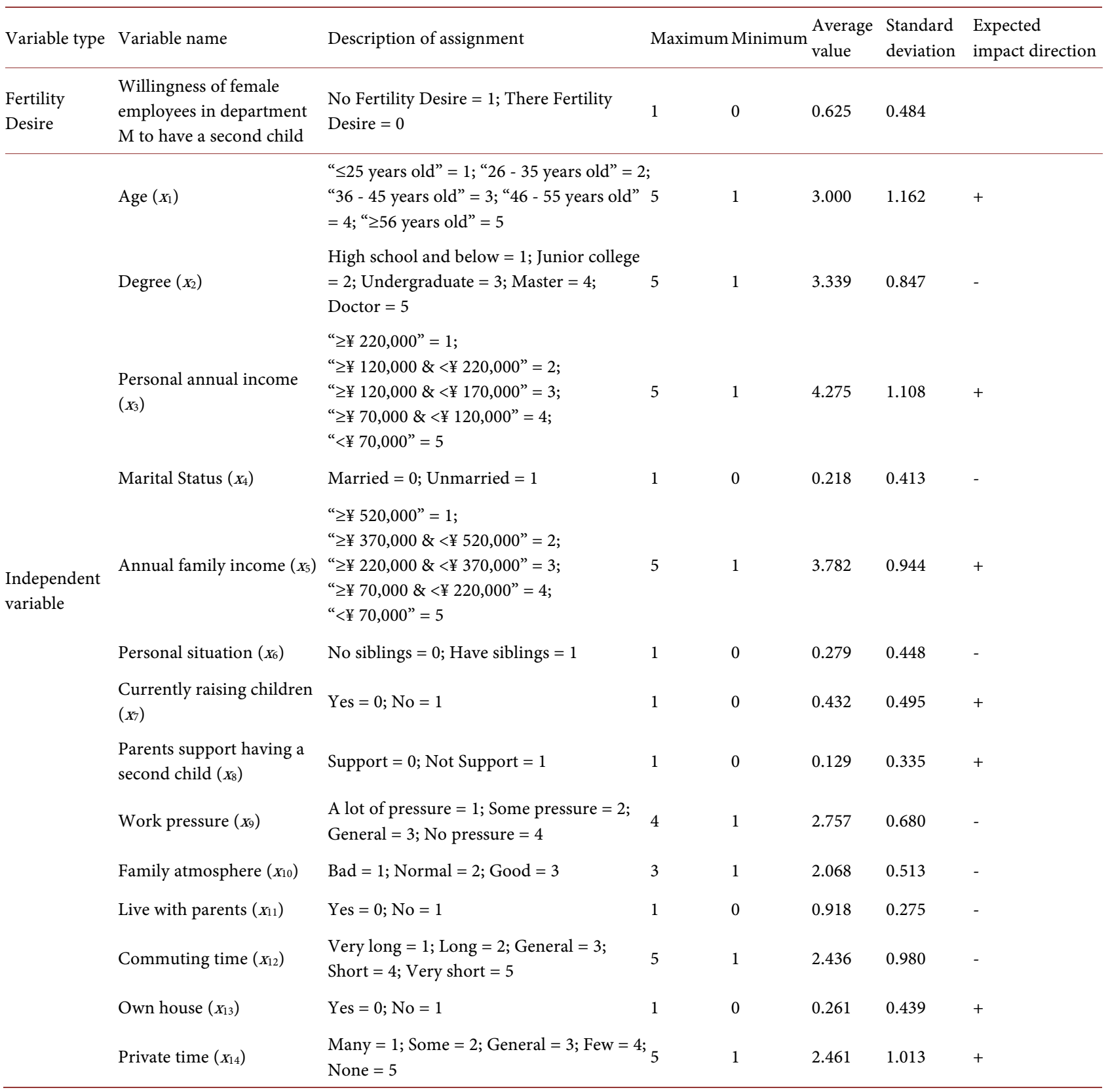




\section{Test Based on Logistic Regression Model}

\subsection{Comprehensive Testing of the Model}

The first step is to process the collected data observations of 280 valid questionnaires. And check whether there are missing values. The data shows that the missing value is 0 . Then check for outliers. No outliers were found in the entire function. Finally, the processing of data standardization is carried out. The data collected by the questionnaire does not need to be standardized because they come from the same department and the data is not very volatile. It can be seen that the questionnaire data is complete and the independent variable test can pass. Data analysis or model building can be performed. When using the binary regression technique in the SAS software Logistic model analysis, the significance level of the independent variable is kept within the $95 \%$ confidence interval. The final calculation results are shown in Table 4.

It can be seen from Table 4 that the values of the comprehensive tests Likelihood Ratio, Score and Wald of the associated independent variables in the model are " $<0.0001$ ", "<0.0001", "0.0106". All three values are less than 0.05 . Therefore, the model check passed.

\subsection{Parameter Estimation and Testing of Independent Variables}

The coefficients of the independent variables $x_{1}, x_{2}, x_{3}, x_{4}, x_{5}, x_{6}, x_{7}, x_{8}, x_{9}, x_{10}, x_{11}$, $X_{12}, X_{13}, X_{14}$ are estimated by maximum likelihood estimation method in the model. The obtained test probability values of each independent variable are 0.4270 , $0.1214,0.1076,0.0084,0.0825,0.0005,<0.0001,0.6428,0.3893,0.9124,0.2960$, $0.1166,0.0419,0.3818$ in order. Among them, $x_{4}(p=0.0084), x_{5}(p=0.0825), x_{6}(p$ $=0.0005), \mathrm{x}_{7}(p \leq 0.0001)$ and $\mathrm{x}_{13}(p=0.0419)$ are all less than the given value 0.1 . It means the inspection passed. That is to say, the regression coefficients of Marital Status $\left(x_{4}\right)$, Annual family income $\left(x_{5}\right)$, Personal situation $\left(x_{6}\right)$, Currently raising children $\left(x_{7}\right)$ and Own house $\left(x_{13}\right)$ have statistically significant differences. The test probability values of the remaining independent variables are all insignificant.

\subsection{Model Analysis}

According to the calculation results of SAS software, the model results are as follows:

$$
\ln \frac{P_{i}}{1-P_{i}}=y_{i}
$$

Table 4. Comprehensive testing of the model.

\begin{tabular}{cccc}
\hline Test & Chi-Square & DF & Pr $>$ ChiSq \\
\hline Likelihood Ratio & 231.6816 & 35 & $<0.0001$ \\
Score & 164.0659 & 35 & $<0.0001$ \\
Wald & 57.1043 & 35 & 0.0106 \\
\hline
\end{tabular}




$$
y_{i}=2.6904 x_{4}+3.5935 x_{5}+2.4707 x_{6}-3.7423 x_{7}+1.9388 x_{13}
$$

For the reduction of Formula (3), the probability value can be expressed as Formula (4):

$$
P(y=1 \mid x)=\frac{\exp \left(2.6904 x_{4}+3.5935 x_{5}+2.4707 x_{6}-3.7423 x_{7}+1.9388 x_{13}\right)}{1+\exp \left(2.6904 x_{4}+3.5935 x_{5}+2.4707 x_{6}-3.7423 x_{7}+1.9388 x_{13}\right)}(4)
$$

According to Formula (4), this function is an increasing function. Therefore, if you want to make the probability value of $P(y=1 \mid x)$ larger (that is, $y_{i}$ becomes larger), the values of the independent variables $x_{4}, x_{5}, x_{6}$, and $x_{13}$ have to become larger and the value of the argument $x_{7}$ must be smaller. (Table 5)

\section{Analysis of Influencing Factors}

By using Logistic binary regression to analyze and process the statistical results of the questionnaire, the results can be obtained. "Personal marital status", "family annual income", "whether I have brothers and sisters", "whether I am currently raising children" and "whether I own my own house" these factors will affect the willingness of female employees in Department M. Therefore, the analysis of the influencing factors and the causes behind them is as follows.

1) Marital factors

$83.6 \%$ of unmarried female employees are unwilling to have a second child. The percentage of married female employees who are willing to have a second child has risen to $43.3 \%$. It shows to a certain extent that marriage can enhance personal family responsibility. The birth plan of married people often precedes that of unmarried people (Whitford \& Hillan, 1998). Especially married people who have given birth to children may desire more for the second child due to emotional and family requirements, so married people are more willing to have a second child than unmarried people.

On the other hand, as the research of Upchurch, Lillard and Panis (2002) shows, married people will agree with the view that "family with children is a happy family" more than unmarried people (Upchurch, Lillard, \& Panis, 2002). Therefore, in order to build a happy family in their minds, married people are more eager to have a second child than unmarried people.

2) The cost of raising children is high

Through analysis of data, high economic pressure is one of the main reasons why female employees in Department $\mathrm{M}$ are unwilling to have a second child. $74 \%$ of female employees with an annual family income of less than RMB 220,000 stated that they were unwilling to have a second child. And in an interview, a female employee once said that the cost of raising children in today's society is very high.

Table 5. Point estimate.

\begin{tabular}{cccccc}
\hline Effect & $X_{4}$ & $X_{5}$ & $X_{6}$ & $X_{7}$ & $X_{13}$ \\
\hline Point Estimate & 14.738 & 36.362 & 11.830 & 0.024 & 6.950 \\
\hline
\end{tabular}


If the first child is compared to a necessity, then the second child is definitely a luxury in the traditional Chinese concept. The child's food and clothing alone need at least RMB 1000 per month. After the child starts school, the money that needs to be invested in the child is about 20,000 RMB each year. Although China currently implements nine-year compulsory education, all kinds of extra-curricular tuition classes and interest classes require at least RMB 5000. And most of the fathers and mothers in Chinese families are engaged in work. Therefore, it is inevitable to spend energy and effort on housekeeping staff or childcare fees. At present, the people's investment in childcare and education has become the main factor affecting the willingness to have a second child.

On the other hand, in addition to necessary consumption, female employees' uncertainty about the future economic level is also one of the main influencing factors. With the reform of Chinese urban social security and economic system, the cost of families buying houses for children's education, medical care, and marriage has greatly increased. In the end, the cost of raising children rose sharply (Wei \& Zhang, 2011). Especially if the overall income of the family is not high, these high parenting costs will make people give up the desire to have a second child.

In addition, the marginal cost effect that children bring to their parents is gradually weakening. Young people in modern society have a wide range of hobbies. Many people no longer focus all their attention on their children. They have advance plans for their pension issues. Therefore, their demand for children will be reduced. Therefore, it is difficult to transform it into actual reproductive activities when faced with such a high cost of living, even if there is a willingness to give birth.

3) Growth environment

The proportion of female employees who have no siblings in the Department $\mathrm{M}$ who are willing to give birth to a second child is $47.5 \%$ of the total number. This data is far greater than the willingness to give birth to female employees with brothers and sisters. Although this result is unexpected after all, it can be explained by combining Chinese national conditions. Most of the female employees in the Department $\mathrm{M}$ are between 26 and 55 years old. Female employees in this age group were born in the 1970s, 1980s and 1990s. At that time, China had just begun to reform and open up, and many families were still in a relatively poor state in the early days (Hrubec, 2020). Therefore, families with many children are prone to unfair parenting due to financial problems. Although the relationship between brothers and sisters is very good, it is precisely because a family has to raise several children at the same time, so these people with brothers and sisters may be in a state of poverty in their childhood. Therefore, this part of the population has worries and fears about the financial cost of raising multiple children. And those female employees who have been alone since childhood will feel lonely and even envy peers with siblings because they have no siblings. Therefore, this part of the population is more inclined to have a 
second child because they don't want their children to have a lonely childhood because they have no brothers or sisters.

As a female employee in the interview said, "I want to have two children." Although she currently has no children, she shared her thoughts. She said that she had no siblings when she was a child. She often sits alone among a pile of toys and talks to herself, which leaves no fond memories of her childhood. Therefore, she believes that in the process of children's growth, the significance of partners is no less than parental care.

4) Family situation and external conditions

At present, the number of female employees who are not raising children willing to have a second child accounts for $47.9 \%$ of the total. Most female employees who have raised children are unwilling to have a second child. And the proportion of people who are unwilling to have children is as high as $70.4 \%$. Many female employees said that raising one child is hard enough now, let alone two. Especially in the public sector like Department $M$, female employees are unlikely to give up the good job of civil servants. Therefore, in such a dual-career family, raising two children at the same time becomes a big problem.

In addition, some interviewees said that it is too difficult for children in China to go to school. $45.8 \%$ of female employees who own their own houses are willing to have a second child. And only $13.6 \%$ of female employees who do not have their own houses are willing to have a second child. This is because China has a unique "hukou" system. As Song and Smith (2021) researched, the house is related to whether a child can go to school (Song \& Smith, 2021). Therefore, whether to own a house is also an important factor affecting female employees' willingness to have a second child.

Another interviewee also shared her experience. She and her husband spent all their savings to buy a school district house. If according to the policy of previous years, her child can directly enroll in school. But when enrolling this year, the school said that the owners of second-hand houses need to go back and wait for news. Only after the owner of the first-hand house has signed up can they go to school if there are places available. Therefore, it is very difficult to provide good educational conditions for the second child when giving birth to a second child. Female employees who are raising children do not want to have a second child because they are well versed in the difficulties that they face when raising children.

\section{Conclusion}

In summary, according to the results, different historical periods and different birth policies will have an impact on the willingness of female employees in the public sector to have a second child, especially in the period when China is carrying out market-oriented reforms. Although the child-bearing policy is relatively loose, the government has gradually expanded the scale of non-governmental organizations. The formation of a dual labor market structure has led to 
a decline in the salary of civil servants like Department $M$ employees. Therefore, severe parenting costs and their own development situation have become the main reasons why many female employees fail to translate their childbearing wishes into realistic childbearing activities. Even overall, $62.5 \%$ of the female employees in the Department $M$ are unwilling to have a second child. Therefore, economic factors and family conditions will be the main factors affecting female employees' willingness to have a second child.

\section{Conflicts of Interest}

The author declares no conflicts of interest regarding the publication of this paper.

\section{References}

Clark, J. (2021). The Ineffectiveness of China's Two-Child Policy. Footnotes, 14, 104-113.

Hrubec, M. (2020). From Chinese Reform to the World's Reform. International Critical Thought, 10, 282-295. https://doi.org/10.1080/21598282.2020.1778969

Krosnick, J. A. (2018). Improving Question Design to Maximize Reliability and Validity. In D. Vannette, \& J. Krosnick (Eds.), The Palgrave Handbook of Survey Research (pp. 95-101). Cham: Palgrave Macmillan. https://doi.org/10.1007/978-3-319-54395-6 13

Leibenstein, H. (1974). An Interpretation of the Economic Theory of Fertility: Promising Path or Blind Alley? Journal of Economic Literature, 12, 457-479.

MacDonald, K. (1997). Life History Theory and Human Reproductive Behavior. Human Nature, 8, Article No. 327. https://doi.org/10.1007/BF02913038

Song, Q., \& Smith, J. P. (2021). The Citizenship Advantage in Psychological Well-being: An Examination of the Hukou System in China. Demography, 58, 165-189. https://doi.org/10.1215/00703370-8913024

Stier, H., Lewin-Epstein, N., \& Braun, M. (2012). Work-Family Conflict in Comparative Perspective: The Role of Social Policies. Research in Social Stratification and Mobility, 30, 265-279. https://doi.org/10.1016/j.rssm.2012.02.001

Upchurch, D. M., Lillard, L. A., \& Panis, C. W. (2002). Nonmarital Childbearing: Influences of Education, Marriage, and Fertility. Demography, 39, 311-329. https://doi.org/10.1353/dem.2002.0020

Van de Kaa, D. J. (2002). The Idea of a Second Demographic Transition in Industrialized Countries. Paper Presented at the 6th Welfare Policy Seminar of the National Institute of Population and Social Security, Tokyo, 29 January 2002, Article No. 45.

Wei, S. J., \& Zhang, X. (2011). The Competitive Saving Motive: Evidence from Rising Sex Ratios and Savings Rates in China. Journal of political Economy, 119, 511-564. https://doi.org/10.1086/660887

Whitford, H. M., \& Hillan, E. M. (1998). Women's Perceptions of Birth Plans. Midwifery, 14, 248-253. https://doi.org/10.1016/S0266-6138(98)90097-3

Wright, R. E. (1995). Logistic Regression. In L. G. Grimm, \& P. R. Yarnold (Eds.), Reading and Understanding Multivariate Statistics (pp. 217-244). Washington DC: American Psychological Association.

Wu, L., Huang, Z., \& Pan, Z. (2021). The Spatiality and Driving Forces of Population Ageing in China. PLoS ONE, 16, e243559.

https://doi.org/10.1371/journal.pone.0243559 
Zeng, Y., \& Hesketh, T. (2016). The Effects of Chinese Universal Two-Child Policy. The Lancet, 388, 1930-1938. https://doi.org/10.1016/S0140-6736(16)31405-2

Zhang, H., Zhang, H., \& Zhang, J. (2015). Demographic Age Structure and Economic Development: Evidence from Chinese Provinces. Journal of Comparative Economics, 43, 170-185. https://doi.org/10.1016/j.jce.2014.07.002

Zhang, L., \& Xia, S. (2017). On Fertility Willingness of Young Women in Rural Areas and Its influencing Factors Under Universal Two-Child Policy-Taking H Town in Nanyang of Henan Province as an Example. Journal of Yibin University, 1, 44-48. 